\section{Anaphylaxis After Cutaneous Application of Argan Oil}

de las Marinas Alvarez MD ${ }^{1}$, Martorell Calatayud $\mathrm{C}^{1}$, Castillo Fernandez $\mathrm{M}^{2}$, Alvariño Martín $\mathrm{M}^{1}$, Félix Toledo $\mathrm{R}^{1}$, Pineda de la Losa $\mathrm{F}^{2}$, Cerdá Mir JC ${ }^{1}$, Martorell Aragonés A ${ }^{1}$

${ }^{1}$ Allergology Service, Consorcio Hospital General Universitario de Valencia, Valencia, Spain

${ }^{2}$ Applications Laboratory, DIATER Laboratorios, Madrid, Spain

J Investig Allergol Clin Immunol 2021; Vol. 31(4): 332-334 doi: 10.18176/jiaci.0596

Key words: Argan. Cutaneous contact. Anaphylaxis. Immunoblotting. Food allergy.

Palabras clave: Argan. Contacto epicutáneo. Anafilaxia. Inmunodetección. Alergia alimentaria.

Argan oil is an edible oil that is obtained by pressing mature seeds from the berry of the argan tree (Argania spinosa), which is endemic to Morocco. It is used in food, cosmetics, and hair care [1] and, since 1980, has become an increasingly popular ingredient in the international cosmetics industry. Consequently, argan oil is increasingly used in Spain.

Only 1 case of anaphylaxis to argan oil [2] and 2 cases of allergic contact dermatitis have been described to date $[3,4]$.

Cutaneous sensitization to foods can induce food allergy through skin care treatments containing food products in adults [5].

Below, we describe the first case of anaphylaxis triggered by the topical application of a product containing argan oil.

The patient was a 29 -year-old woman diagnosed in childhood with allergic rhinoconjunctivitis to domestic mites and grass pollen that had progressed since adolescence to allergy to peanuts, peach, and other rosaceae (apricot, plum, cherry), as well as to nuts (hazelnut, walnut, chestnut) and mustard. She also experienced symptoms of generalized urticaria and oral allergy syndrome with various vegetables (courgette and aubergine). She did not report a history of atopic dermatitis.

The patient requested a consultation after experiencing 2 anaphylactic episodes during the previous 4 years immediately after cutaneous contact with argan oil, which she had previously used in well-tolerated cosmetic preparations. The first episode involved a cosmetic hair care product applied to the scalp (leading to widespread cutaneous pruritus, angioedema, and hypotension), and the second (same manifestations, quicker onset) after application of a body oil to the arm. On both occasions, she required emergency treatment with epinephrine to control the symptoms. She did not report food intake or presence of cofactors with either event. Since then, she has been prescribed self-injectable epinephrine. The patient denied ever having ingested argan oil as a food seasoning.

Skin prick tests (SPTs) performed with a standard battery of aeroallergens and several foods yielded positive results to pollen (grass, Salsola species, and mugwort), dust mites, peanut, lipid transfer protein (LTP, peach peel), mustard, tarragon, and cumin. Skin tests for other foods such as nuts (almonds, hazelnuts, sunflower seeds, cashew, pistachio, walnut, pine nut), spices (cardamom, clove, coriander), and sesame seeds were negative. All tests were performed following EAACI guidelines [6]. A positive test result was defined as a wheal of at least $3 \mathrm{~mm}$.

Determination of serum specific IgE (sIgE) (ImmunoCAP, Thermo Fisher Scientific) revealed the following values: mustard, $0.12 \mathrm{kU}_{\mathrm{A}} / \mathrm{L}$; peanut, $0.34 \mathrm{kU}_{\mathrm{A}} / \mathrm{L}$; peach, $0.75 \mathrm{kU}_{\mathrm{A}} / \mathrm{L}$; walnut, $0.54 \mathrm{kU}_{\mathrm{A}} / \mathrm{L}$; and Pru p 3, $0.99 \mathrm{kU}_{\mathrm{A}} / \mathrm{L}$.

sIgE to a panel of 112 allergens was also evaluated using ImmunoCAP ISAC microarray (Thermo Fisher Scientific). The results were expressed as ISAC standardized units (ISU), with a cut-off of 0.3 ISU. ISAC revealed sensitization to species-specific components of grass pollen ( $\mathrm{rPhl} \mathrm{p} \mathrm{1,} 9.9$ ISU; rPhl p 5, 3.0 ISU), Salsola pollen (nSal k 1, 2.4 ISU), and dust mites (nDer p 1, 1.1 ISU; nDer f 1, 1.3 ISU), as well as marker components of cross-reactivity (nsLTP) in walnut (nJug r 3:0.7 ISU), peach (rPru p 3, 0.6 ISU), and mugwort (nArt v 3, 0.7 ISU). Findings were negative for all other native and recombinant allergens in the panel.

For the study of the specific allergy to argan, berries were collected directly from the tree in Morocco to prepare the extract. Skin tests with argan berry extract $(7.39 \mathrm{mg} / \mathrm{mL})$ were positive $(10 \times 12 \mathrm{~mm})$ at a dilution of $1 / 10$. A provocation test was not considered, owing to the severity of the symptoms resulting from cutaneous contact with the products.

A prick test conducted with 2 healthy controls and 5 atopic controls sensitized to peach LTPs was negative at a concentration of $1: 1$.

Western blot analysis (Figure, A) of the Argan extract (water-soluble fraction) revealed that several protein bands at 10, 14, 18, 20, 32-34, and $48 \mathrm{kDa}$ (Figure, B) fixed the patient's IgE, with immunodetection being negative for the external-internal coverings of the extracts and very slight for the fat-soluble fraction [7]. The presence of bands of $\operatorname{IgE}$ binding to proteins of other plant-based foods (walnut, peach, peanut, sesame, and mustard) was investigated and proved negative for peanut, walnut, and sesame seed, with several bands being revealed for mustard $(10,14,15,21,27,30$, and $34 \mathrm{kDa}$ ) and 1 of 13-15 kDa for peach (Figure, B). 
A

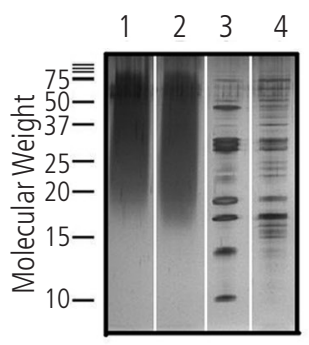

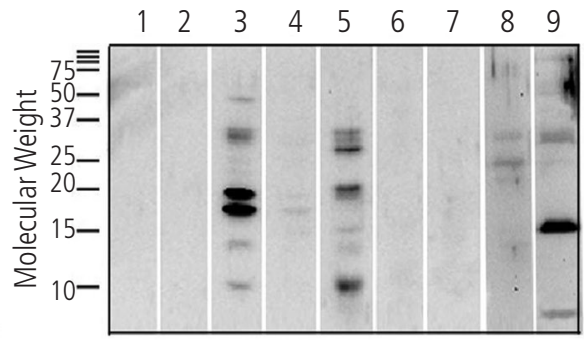

C

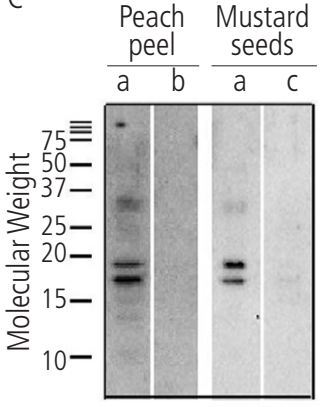

D

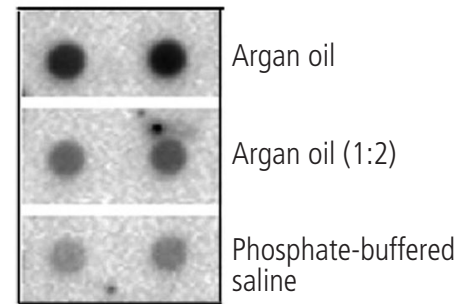

Figure. A, SDS PAGE. Molecular weight marker. Lane 1, argan berry wall; lane 2, argan berry peel; lane 3, argan water-soluble extract; lane 4, argan fat-soluble extract. B, IgE-Western blot. Molecular weight marker. Lane 1, argan berry wall; lane 2, argan berry peel; lane 3, argan water-soluble extract; lane 4, argan fat-soluble extract; lane 5, mustard seeds; lane 6, walnut; lane 7, sesame seeds; lane 8, peanut; lane 9, peach peel. C, IgE-Western blot inhibition: solid phase: lane a: argan water-soluble extract; lane b: peach peel; lane c: mustard seeds. Inhibitory phase: peach peel and mustard seeds; in both "a lines" respectively. D, IgE-DOT blot. Argan oil, 1:2 diluted argan oil, and phosphate-buffered saline.

Immunoblotting inhibition (Figure, C) performed for argan berries, with preincubation with both peach and mustard, resulted in inhibition of binding in several previously described bands $(10,14,32-34$, and $48 \mathrm{kDa})$ and the persistence of bands at 18 and $20 \mathrm{kDa}$, which do not correspond to the predicted molecular weight for peach LTP (Pru p 3, 8-10 kDa) or mustard LTP (Sin a 3, $12 \mathrm{kDa})$.

Dot blot [8] with argan oil was positive (Figure, D).

We present the first case of allergy to argan berries manifesting as anaphylaxis after cutaneous contact with argan oil in a woman sensitized primarily to peach LTP (Pru p 3).

Cutaneous contact has been reported to be a possible inducer of $\operatorname{IgE}$ hypersensitivity with various food allergens (peanut, wheat, fish, jellyfish, milk, and rice) on skin affected by atopic dermatitis, irritative skin, and healthy skin [9], thus demonstrating the possibility of subsequent anaphylaxis after ingestion. Hypersensitivity has also been induced after further cutaneous contact subsequent to sensitization [10].

In the case we report, immunoblotting revealed serum specific IgE against proteins of $18 \mathrm{kDa}$ and $20 \mathrm{kDa}$ in argan berries. This IgE persists after preincubation with peach or mustard extract and may be responsible for the anaphylactic symptoms, regardless of primary sensitization to LTP. The existence of a positive dot blot result with argan oil demonstrates that proteins in the berries that have caused sensitization in the patient remain in the oil.

The patient also seemed to have specific IgE to mustard, in contrast with other, non-LTP-dependent proteins present in the extract.

The only case of anaphylaxis owing to the intake of argan oil reported to date [2] was that of a Moroccan male, in whom a $10-\mathrm{kDa}$ protein band was described. This may correspond to the band of a similar molecular weight found in the present case. Two cases of allergic contact dermatitis have also been reported $[3,4]$, although there have been no further cases of anaphylaxis owing to the cutaneous application of a product containing argan oil.

Given the increasingly widespread use of argan in food and cosmetics, more cases of allergy to this product are likely to be encountered in the future.

\section{Funding}

The authors declare that no funding was received for the present study.

\section{Conflicts of Interest}

The authors declare that they have no conflicts of interest.

\section{References}

1. Khallouki $F$, Younos $C$, Soulimani $R$, Oster $T$, Charrouf $Z$, Spiegelhalder $B$, et al. Consumption of argain oil (Morocco) with its unique profile of fatty acids, tocopherols, squalene, sterols and phenolic compounds should confer valuable cancer chemopreventive effects. Eur J Cancer Prev. 2003;12:67-75.

2. Astier C, Benchad Yel A, Moneret-Vautrin DA, Bihain BE, Kanny G. Anaphylaxis to argan oil. Allergy. 2010;65:662-3.

3. Barrientos N, Moreno de Vega M, Dominguez J. Allergic contact dermatitis caused by argan oil in an infant. Contact Dermatitis. 2014;71:316-7.

4. Foti C, Romita P, Ranieri LD, Bonamonte D. Allergic contact dermatitis caused by argan oil. Contact Dermatitis. 2014;71:183-4.

5. Inomata N, Nagashima M, Hakuta A, Aihara M. Food allergy preceded by contact urticaria due to the same food: involvement of epicutaneous sensitization in food allergy. Allergol Int. 2015;64:73-8.

6. Van Kampen V, de Baly F, Folleti I, Kobiersi P, Mocato G, Olivieri $M$, et al. EAACl position paper: skin prick testing in the diagnosis of occupational type 1 allergies. Allergy. 2013;68:580-4.

7. Barbarroja-Escudero J, Sanchez-Gonzalez M-J, AntolinAmerigo D, Rodriguez-Rodriguez M, Pineda F, Alvarez-Mon M. Diagnosis of IgE-mediated hypersensitivity to sesame seeds supplemented with lipid body proteins. Allergol Int. 2015;64:396-8.

8. Slott DI. Immunoblotting, Dot-Blotting, and ELISPOT Assays: Methods and Applications. J Immunoassay. 2000;2:273-96. 
9. Bahna SL. Adverse food reactions by skin contact. Allergy. 2004;59 (Suppl.78):66-70.

10. Oranje AP, Aarsen RS, Mulder PG, Van Toorenenbergen AW, Liefaard G, Dieges PH. Food immediate-contact hypersensitivity (FICH) and elimination diet in young children with atopic dermatitis. Acta Derm Venereol (Stockh). 1992;176:41-4.

Manuscript received May 17, 2020; accepted for publication September 7, 2020.

Maria Dolores de las Marinas Alvarez Consorcio Hospital General Universitario de Valencia Allergology Service Av Tres Cruces $n^{\circ} 2$ 46014 Valencia (Spain).

E-mail: ddelasma@yahoo.es 